\title{
Diversifying the Structures of Local Higher Education Resources
}

\author{
Huarong Dong ${ }^{1, *}$ \\ ${ }^{1}$ Wuhan Research Institute, Jianghan University, Wuhan 430056, China \\ *Corresponding author. Email:349669790@qq.com

\begin{abstract}
The main objective of this study is to provide local colleges and universities with theoretical and methodological references to improve their competitive advantages comprehensively and make the most of their unique advantages in relation to talent training, scientific research, social service, and culture the following conclusions. Local colleges and universities are open to society, seek to deepen their relationship with society, make full use of social resources, and share educational resources widely with society. The self-oriented, inclusive, and two-way communication in cooperation with schools and communities fosters an adequate educational ecology that results in a mutually beneficial situation. Keywords: local higher education, resource diversification, quality, social service
\end{abstract} \\ inheritance. Using various research methods, such as a literature survey and data reference, this study draws
}

\section{INTRODUCTION}

Since the rise of audiovisual education in the 1930s, the variety of media available has become increasingly extensive, and concepts in education have changed accordingly. In the early days, teachers were regarded as sources of information, and, similarly, the role of media was limited to a one-way transmission of knowledge from teachers to students, who were simply passive learners. In the 1970s, it was recognized that students were the main participants in learning activities, and media became a means of facilitating communication between teachers and students. This reflected an educational ideal, namely, that such communication should be promoted. In the 1980s, the media was no longer a mere "channel" to convey information but a practical space and field of cognitive activity. People paid more attention to and focused more on the media environment. In the 1990s, an increasing emphasis was placed on the importance of educational resources, and it became an urgent task for local colleges and universities to accumulate such resources and to strengthen their understanding of and research on these resources.

A new scientific, technological, and industrial revolution is gaining momentum around the world. Innovation has become the pinnacle of rivalry among major countries, and competition for talent is becoming increasingly fierce. The general requirement of education in China is to fully implement the spirit of the 18th Chinese Communist Party (CPC) National Congress and the Third, Fourth, and Fifth Plenary Sessions of the 18th CPC Central Committee and to use the Deng Xiaoping Theory, the important thought of the "Three Represents," the concept of scientific development as guidance, in-depth study, and the thoughts of Xi Jinping as described in his important speeches. The
General Secretary, in accordance with the overall "Five One" layout and the "Four Comprehensives" strategic layout, set forth the concepts of innovation, coordination, green development, openness, and the sharing of ideas. The party's education policy is to be fully implemented and closely connected with the theme of improving the quality of education. The strategy, with khalid ents as a fundamental task, is to promote fairness as a basic requirement, to undertake the optimization of structures, to deepen the reform of basic powers, to improve the rule of law as a reliable guarantor, and to strengthen the leadership of the party as a strong guarantee.

We will accelerate the modernization of education and play a key supporting role in building a moderately prosperous society in all respects. Development is the absolute principle, basis, and key to solving all problems. Accordingly, development must be scientific, guided by advanced concepts, and must firmly and comprehensively implement the five concepts of innovation, coordination, green development, openness, and sharing set forth at the Fifth Plenary Session of the 18th CPC Central Committee. Under the guidance of the overall national strategy and grand blueprint, local colleges and universities should plan for the systematic reform and development of education.

\section{RESEARCH PROPOSAL}

Educational resources can be understood as those that encompass the material, natural, social, and media conditions that may be used in education and teaching and act as sources of teaching materials and information. In the context of educational resources, local colleges and universities should take initiative to open up to society, deepening their relations with it, making full use of social resources, sharing educational resources more widely, and 
cultivating a suitable educational ecology with the cooperation of schools and the community.

\section{THE DIVERSIFICATION OF LOCAL HIGHER EDUCATION RESOURCES}

Educational resources fall into two categories: designed and utilized. These may include teaching materials, the teaching environment, and teaching support systems. Teaching resources, colloquially speaking, refer to all the materialized, explicitly or implicitly, elements of teaching that can help students achieve their learning goals and advance their learning. Textbooks, for example, are materialized resources in learning; textbooks comprise the material for students to make use of in the learning process under the guidance of their teachers. Textbooks require teachers' secondary processing and must be developed and used scientifically and reasonably in combination with students' characteristics.

Similarly, computers represent another media element and a resource in teaching. Ideal methods for integrating computers into the curriculum and maximizing the role of modern information technology not only reflect teachers' understanding but also their ability to control this new technology. The learning situation is a component of teaching that depends on the creativity of teachers. A good learning situation will help students achieve double the result with half the effort.

The traditional library and data center cannot adapt to everchanging knowledge in the information age. The development of network technology has provided the most extensive teaching resources for students. Online educational resources exist in various forms and types. Understanding the types and characteristics of educational resources will be conducive to acquiring resources efficiently and employing them optimally in actual teaching. In this manner, large-scale student participation and strict quality control become possible. Moreover, widespread access to mature technologies facilitates access to high-quality and low-cost higher education in local colleges and universities.

\section{THE COMPOSITION OF DIVERSIFIED LOCAL HIGHER EDUCATION RESOURCES}

The term "educational resources," in a broad sense, describes all elements used by educators in the teaching process, including those who support and serve teaching, whether in terms of finance, materials, information, and so on. This sense may even extend so far as to include educational policy.

\subsection{Open Educational Resources with "Teaching Quality as the Purpose"}

Yuan Guiren delivered a speech at the 2016 National Education Work Conference on "comprehensively improving the quality of education and accelerating the modernization of education guided by the new development concept" [1]. He asserted that colleges and universities should strengthen their advantages and characteristics in particular disciplines, identifying their objectives independently while avoiding the pursuit of mediocrity. For its part, the government should strengthen performance evaluation and dynamically adjust the intensity of support means according to the success with which each university realizes its goals, thereby avoiding perpetually increasing support. An open mechanism should be established to adjust the supported disciplines in a timely way, thus avoiding identity solidification. A prominent role would be played by big data, focusing on published data, results, and quality reports and guiding colleges and universities to focus on daily quality improvement and achievement at the highest levels. Schools should comprehensively assess teaching quality in the form of teacher self-evaluations, student evaluations, peer evaluations, and supervision evaluations [2].

At present, the essence of the modernization of education constitutes open education with "teaching quality as the purpose." The movement to develop open education resources passed through three stages in succession: from open courseware projects, to open education resources, and, finally, to massive open online courses. Open resources have transitioned from relatively simple, static curriculum materials to a complete process of teaching and learning. The Massachusetts Institute of Technology played a key role in initiating this process, which has spread to 45 countries and regions around the world, involving more than 250 universities and scientific research units. By their very nature, open courseware projects, open education resources, and massive open online courses serve as carriers and basic units of the sharing of open education resources. The scope of open education resources is larger than the open courseware projects involved in massive open online courses. These courses are merely the latest development of what are collectively known as open education resources. The rise and development of the open education resources movement not only redefines courses and modes of knowledge transmission in the network age but also highlights the role of the university in the intrinsic pursuit of knowledge creation and dissemination. Through the power of network communications and technology, the university's "knowledge" fence is disintegrating, and the diverse distribution of knowledge is becoming increasingly convenient, with an ever-growing depth, breadth, and speed for any individual with an Internet connection. The practical characteristics and underlying concept behind these changes can be summarized as the belief in the importance of knowledge as a public good that is free and openly shared. 


\subsection{Appeals for Educational Resources to Serve Social Needs}

How can local colleges and universities play a role in guiding regional and national economic development, higher education, and the development of social reform? Strengths can be fostered and weaknesses bypassed by establishing a platform for cooperation between cities and universities. This can amplify the benefits of courses, enhance services, vigorously strengthen the exchange of administrative experience, and make fitting contributions to innovations in science, technology, and knowledge in general. Simultaneously, attention should be given to particular management practices and hierarchies in colleges and universities to guide them in forming their own ideas and styles of operation. College education will also face the market, follow the market mechanism, and reform the management mode of teachers and students so that their management will be based more on the value of the law of education, which is a key factor in improving and guaranteeing the quality of education and teaching [3]. Local colleges and universities should have the freedom to develop unique characteristics at different levels and in different fields while striving to become the best. Optimizing the organizational structure of higher education will allow it to become the primary source for the production of talent in science and technology. In accordance with the requirements of the plans for the national economy and urbanization, the establishment of regional higher education centers and the restructuring of institutions of higher learning will strengthen national productivity and social development.

Pertinent to this concept is the "Wisconsin Idea," which originated from the educational practice and philosophy of the University of Wisconsin. During Van Hise's tenure as the President of the University (1903-1918), "social service" was clearly and vigorously advocated as its third function. Hallmarks of Van Hise's viewpoint, such as that "service should be the only idea of a university" and that "the boundary of a school is the boundary of a state," has been labeled collectively as the influential "Wisconsin Idea" [4]. Furthermore, Van Hise said the same of the relationship between social service and CITY University: "The [U]niversity should be a beacon, actively promoting social development, so that people all over the state can connect with the talent and knowledge of the university, so that every family can benefit from this connection." Given the current situation of social development, the position of higher education, and the characteristics of city universities, it is a wise choice for local universities to expand their social service function actively and to emphasize core competitiveness. The traditional university has a high wall and a deep courtyard; the world outside the wall is distinct and does not blend in. However, the modern university, in particular, the local university, which takes service as its duty, should be open to and integrated with society. Educational resources, such as libraries, laboratories, testing centers, audiovisual centers, computing centers, and gymnasiums, can all be properly opened to the public.

Accompanying the popularization of higher education in China, the scale of the institutions themselves is expanding unceasingly. The expansion of colleges and universities has made their classification and positioning unclear and has led to a convergence of aims, copycat upgrading, and the pursuit of popular recognition and high rankings. The situation is particularly pronounced in some local colleges and universities owing to their weak foundations, a lack of excellence, the structure of teachers' questions, limited funds, a lack of ability, poor service levels, and a shortage of social resources. In such cases, there is no need to follow the path of the traditional university and their particular academic pursuits. Instead, initiative must be taken to better serve local economic and social development. By taking a distinct, well-differentiated approach, a school can successfully carve out a niche for itself. Governments at all levels should support the development of local higher education by implementing a "clearer choices but more serious consequences" program for the establishment of institutions of higher learning, optimizing such institutions in accordance with the local economic and social needs and the availability of resources. Local governments at various levels should promote investments in higher education and support regional colleges and universities as well as enterprises, research institutes, and the greater community. Moreover, local colleges and universities should be encouraged to develop unique characteristics and levels.

\section{CONCLUSION}

Under the premise of improving teaching quality, local colleges and universities in China are comprehensively expanding educational resources, accurately assessing their current strength and position, and correctly evaluating their actual situation and the possibility of rejuvenating their educational resources. Guided by a scientific approach to development, we should successfully grasp the strength of operating schools. Exploring a diversified structural model for the development of educational resources in local colleges and universities provides an appropriate foundation for continuous and steady improvement with respect to the overall attainment of the school

\section{ACKNOWLEDGMENT}

This work was supported by the Open Subject Research of the Wuhan Research Institute, Jianghan University (IWHS20192066).

\section{REFERENCES}

[1] Ministry of Education of the People's Republic of China, "The new development concept as the guide to comprehensively improve the quality of education and accelerate the modernization of education -- Speech at 
The 2016 National Conference on Education Work," http://www.moe.edu.cn, 2016.

[2] Ministry of Education of the People's Republic of China, "The guiding opinions of the Ministry of Education on deepening the reform of college teachers' assessment and evaluation system," 2016.

[3] Y. Liwen, "On the change of higher education management model," J. Datong Voc. Tech. College, vol. 3, pp.73-74, 2006.
[4] Y. Zhouqunying and Xiangqiaoli, "A new development of Wisconsin teaching service concept in the 21 st century," University of Wisconsin-Madison, Modern Educational Science (Higher Education Studies), pp. 165-169, November 2018. 